\title{
Las vanguardias artísticas del siglo XX y su contribución teórica en la definición exhibicionista de la naturaleza del cine*
}

\author{
Pedro Sangro Colón**
}

Recibido: 2015-07-15 Enviado a pares: 2015-07-20

Aprobado por pares: 2015-08-19 Aceptado: 2015-08-30

\begin{abstract}
Resumen
A pesar de que las vanguardias artísticas de principios de siglo constituyen un grupo de movimientos heterogéneo coinciden en un ideal común: la ruptura del estatus del arte en la sociedad burguesa. El desplazamiento del sujeto del centro del proceso creador y la aparición de un nuevo sistema de representación basado en la perspectiva múltiple harán que el cine se sitúe en el punto de mira de distintas propuestas rupturistas como el cubismo, el futurismo o el dadaísmo. El objetivo del presente texto es destacar las aportaciones de los movimientos de vanguardia emergentes durante las primeras décadas del siglo XX en la fragua de conceptos teóricos capaces de dotar al cine de un estatus discursivo basado en la forma y la construcción al que denominaremos exhibicionista, que se opone al de su consideración como cine clásico supeditado a suceder a la literatura decimonónica en su misión narrativa.
\end{abstract}

Palabras clave: cine clásico, discurso, vanguardia, teoría fílmica, cubismo, dadaísmo, futurismo.

* El presente artículo expone resultados de la investigación El clasicismo en el cine, una mirada intergeneracional, desarrollada entre febrero de 2015 y abril de 2016 en la Universidad Pontificia de Salamanca. La investigación está realizada por miembros del grupo de investigación Media and Audiovisual Culture, que desarrolla las líneas de investigación: Industrias culturales de TV, radio, cine y música: creación, producción, narrativa, estética, regulación y programación. El proyecto se inscribe dentro de las actividades del Programa interuniversitario de la experiencia en Castilla y León, y cuenta con el apoyo financiero del Ayuntamiento de Salamanca.

* Profesor catedrático de Lenguaje y Narrativa Audiovisual en la Universidad Pontificia de Salamanca y director del Máster de Guion de Ficción para Cine y Televisión. Correo: psangroco@upsa.es 


\title{
The artistic avant-gardes of the $20^{\text {th }}$ century and its theoretical contribution in the exhibitionist definition of Film's nature
}

\begin{abstract}
Although the artistic avant-gardes of the beginning of the $20^{\text {th }}$ century are a heterogeneous group, they all coincide in a common ideal: contravening the status of art of the bourgeois society. Displacing the individual from the centre of the creative process and the appearance of a new system of representation based in a multiple perspective will attract different groundbreaking approaches such as Cubism, Futurism or Dadaism to Film. This paper aims at highlighting the contributions of the emerging avant-garde movements during the first decades of the $20^{\text {th }}$ century to the forge of theoretical concepts that provided films with a discursive status based on forms and structures that we call exhibitionist, as opposed to classic film, which was meant to follow the steps of $19^{\text {th }}$-Century literature in its narrative mission.
\end{abstract}

Key words: Classical Film, Discourse, Avant-Gardes, Film Theory, Cubism, Dadaism, Futurism. 


\section{Introducción}

El arranque del siglo XX acoge un período en el que acontecen fuertes cambios sociales, políticos y económicos, a la par que surgen potentes innovaciones científicas y filosóficas. Paralelamente, la progresión apacible de las artes se trastoca de manera súbita, y la adhesión hasta entonces incuestionable a las mismas es desafiada desde todos los puntos de vista.

En ese tiempo de cambio surge el cinematógrafo, un nuevo invento que en los primeros años de su desarrollo no posee tradición alguna y se esfuerza en la búsqueda de una forma modélica de discurso. Resulta sorprendente que, solo dos décadas después de su nacimiento, la consideración de la naturaleza del cine más aceptada coincida con la del modelo discursivo heredero de la novela decimonónica especializado en contar historias y bautizado por historiadores e investigadores con el apellido clásico.

Las características del cine clásico se resumen en la especificidad narrativa garantizada por la lógica causal que soporta su discurso gracias a las herramientas que favorecen la continuidad cinematográfica -agrupadas bajo el concepto que asume el galicismo rácord-. Su finalidad es contar una historia y favorecer la identificación del espectador al sumergirle en la diégesis ficcional eliminando cualquier rastro que delate que la narración que se despliega ante sus ojos es, en realidad, un artificio construido para guiar su atención. Su apariencia formal se manifiesta, por tanto, paradójicamente, en el ocultamiento de las huellas de la enunciación. Burch (1991) bautiza este modelo discursivo con el nombre de Modo de Representación Institucional (M. R. I.) y analiza sus características a partir de su gestación a lo largo del período correspondiente al cine primitivo comprendido entre 1895 y 1927. La opción lingüística que describe constituye la base del modelo del cine clásico hollywoodiense, definido de forma precisa por Benet (1992) por el sometimiento de su dispositivo técnico y su retórica a la absoluta funcionalidad narrativa de los significantes.

Su protagonismo y liderazgo se extiende, según el denso estudio de Bordwell, Staiger y Thompson (1997), durante el período comprendido entre 1917 y 1960. Esta aplastante hegemonía a lo largo de más de cuatro décadas de la historia del cine provoca que, en ocasiones, el cine clásico se presente como un paradigma excluyente para otras consideraciones de la naturaleza del medio cinematográfico. Pero su propuesta no es la única: las vanguardias artísticas emergentes durante las primeras décadas del siglo XX también acogieron al cine con optimismo, vislumbrando en aquello que parecía solo un mero dispositivo técnico de registro, el potencial para el desarrollo de un nuevo arte autónomo, un nuevo lenguaje capaz de responder a las expectativas de los valores que estos movimientos proponían para la instauración del mundo moderno. Tarde o temprano se acabarán topando con el problema de la definición de su naturaleza y su instrumentalización en una determinada dirección opuesta a la clásica.

\section{Objetivo y metodología}

Partiendo de las premisas expuestas, el presente artículo de reflexión se propone revisar los textos -fuentes directas- legados por los responsables de los movimientos rupturistas 
de principios del siglo XX -cubismo, dadaísmo, futurismo, vanguardia cinematográfica miscelánea y demás experiencias formativas-, considerándolos como una declaración de intenciones de sus prácticas artísticas. El objetivo que se persigue es la destilación de los conceptos teóricos influyentes en la balbuceante teoría en torno al estatus discursivo del cine que emergerá en la inminente vanguardia soviética. El nexo común de todas las propuestas reside -como se verá- en una consideración lingüística del medio -a la que denominaremos exhibicionista - que se opone diametralmente a la opción de naturaleza clásica definida como el paradigma cinematográfico de su discurso.

Atendiendo también a los trabajos de investigación que posteriormente han fijado su atención en el análisis del legado teórico de las vanguardias artísticas -fuentes indirectas-, se empleará una metodología documental de naturaleza cualitativa que aplicará, siguiendo a Sierra (1995) técnicas de trabajo intelectual basadas en la formación de conceptos que posibilitan realizar abstracciones y definiciones; el establecimiento de juicios que permite relacionar, analizar, sintetizar, comparar y clasificar la información en torno a dichos conceptos, y la realización de inferencias que ayudan a inducir y deducir otros nuevos.

\section{Los intereses comunes del cine y las vanguardias}

Sánchez-Biosca (1996) señala diversos factores que refuerzan la tesis de la convergencia del cinematógrafo con los intereses rupturistas de los movimientos de vanguardia. En primer lugar, el cinematógrafo se presentaba como una de las formas menos artísticas, lo que le situaba en sintonía con la técnica y la industria, dos de las más poderosas armas utilizadas por la vanguardia. Además, ponía de manifiesto un altísimo grado de reproductibilidad, haciendo así peligrar la propia definición de obra de arte, resquebrajada ya por el uso masivo de la misma, impuesto desde la invención de la fotografía en el siglo XIX. Por otra parte, el invento de los Lumière entroncaba en sus comienzos con las formas menores del espectáculo, muy del agrado de la mayoría de los movimientos de ruptura. Por último, las vanguardias descubrían en el cine un dispositivo técnico con una capacidad de expresión mecánica ajena a lo humano y, por lo tanto, con disponibilidad para satisfacer uno de sus objetivos básicos: la destrucción del sujeto racional, considerado hasta ese momento como el organizador de la obra de arte y del universo lógico que esta presentaba.

De tales aseveraciones se deduce, en primer lugar, que las vanguardias artísticas consideraron la técnica y la industria como los conceptos protagonistas de una nueva etapa en la historia del arte, propiciando así la necesidad de volver a definir el perfil del artista. Además, el hecho de que el cine y la fotografía culminasen una tendencia a la reproducción, entendida según el clásico texto de Walter Benjamin La obra de arte en la era de su reproductibilidad técnica -publicado originalmente en 1936 y recogido en el compilado del autor Discursos interrumpidos I: Filosofía del arte y de la historia (1987)-, les convirtió en los primeros medios de masas en los que el concepto de autoría artística quedaba en entredicho:

En la época de la reproducción técnica de la obra de arte lo que se atrofia es el aura de ésta. El proceso es sintomático; su significación señala por encima del ámbito 
artístico. Conforme a una formulación general: la técnica reproductiva desvincula lo reproducido del ámbito de la tradición. Al multiplicar las reproducciones pone su presencia masiva en el lugar de una presencia irrepetible (p. 22).

El tercero de los factores que alienta la simbiosis entre las vanguardias artísticas y el cine es el carácter popular que se desprende de sus comienzos como espectáculo ferial. No cabe duda de que algunos conceptos clave elaborados en el seno de las teorías del montaje soviético -como el de atracción o el de extrañamiento- no pueden ser entendidos sin el contexto vanguardista e interdisciplinar en el que se fragua la naturaleza del medio, en el que los llamados espectáculos menores (vodevil, circo, music hall, etc.) son tan partícipes como las aportaciones individuales de los pioneros forjadores del supuesto y omnipresente modelo narrativo del cine clásico americano.

Finalmente, destaca también el interés suscitado por las vanguardias al entender que el cine no es sino una máquina, lo que será un factor de enorme importancia para el posterior desarrollo del constructivismo soviético y las primeras concepciones teóricas sobre el poder discursivo del nuevo medio. Se debe recordar, al respecto, que el uso científico de todos los procedimientos anteriores al cinematógrafo de los hermanos Lumière - desde el fenaquitoscopio de Plateau hasta el cronógrafo de Muybridge- se alejaba tanto del modelo espectacular derivado de las atracciones de feria como del tópico burgués de la búsqueda del Modelo de Representación Institucional descrito anteriormente, centrándose más en el estudio de la descomposición del movimiento humano para abrir una primera puerta al taylorismo: así lo prueban, por ejemplo, los experimentos de JulesÉtienne Marey que usaban los aparatos antecedentes del cinematógrafo como tecnologías al servicio de la observación y el análisis científico de modelos de movimiento imperceptibles para el ojo humano, captados mediante imágenes y procedimientos puramente mecánicos.

Sumidos en este caldo de cultivo, y a pesar de no tener una intervención directa en el cine, algunos movimientos de la vanguardia artística anticipan las primeras ideas que desgarran el orden figurativo para terminar con la consideración estética de la obra de arte impuesta desde el Renacimiento, preparando así el camino para que otras proposiciones rupturistas con abordaje directo en el cine -las vanguardias soviéticas y sus teorías sobre el montaje cinematográfico-alberguen ya un nuevo modelo discursivo alejado de la narrativa transparente clásica.

\section{Aportaciones del cubismo: signo y collage}

Aunque se suele citar a Cézanne como claro antecedente del cubismo por ser el primero en renunciar al uso de la perspectiva clásica para conseguir dotar de profundidad sus pinturas -técnica llamada de los passages que consistía en estructurar el espacio en dos zonas cromáticas diferentes-, todos los autores coinciden en que el nacimiento del movimiento se produce en 1907 al ver la luz la obra Las señoritas de Avignon, de Pablo Picasso. Se puede, por tanto, señalar ese año como el momento en el que, por primera vez desde el Renacimiento, cambia la relación entre la imagen pintada y la realidad. 
A este respecto, el ensayo de Francastel (1984) estudia la evolución del sistema de representación pictórico desde el Quattrocento hasta el cubismo, y concluye que la perspectiva lineal no era el único sistema conocido en la época renacentista. Sin embargo, señala el autor, se impuso hasta finales del siglo XIX siendo, contradictoriamente, un modo de expresión convencional -en ningún caso único ni realista-, resultado de un cierto estado de las técnicas, la ciencia y el orden social del mundo en el momento de su aparición. Si transportamos esta tesis al estudio del cubismo, se puede considerar entonces que el movimiento alumbra el principio de un nuevo sistema preparado para sustituir al del Quattrocento por los mismos motivos por los que este superó al anterior: la decadencia de una determinada forma de representación de la sociedad ante la transformación de la misma.

La posición del hombre frente a la realidad evoluciona según la representación espacial que de ella establece en cada momento. Así, en el Renacimiento, el modelo de representación pictórico era el del espejo, organizado de tal forma que el hombre ocupaba el lugar del ojo para el que la realidad había sido hecha visual. Después, se sucederán diferentes modelos hasta la llegada del propuesto por el cubismo, al que Berger (1990) denomina diagrama: "El diagrama es una representación visible, simbólica de procesos, fuerzas y estructuras invisibles. El diagrama no tiene que evitar ciertos aspectos de las apariencias, pero estos serán también tratados simbólicamente como signos, no como imitaciones o recreaciones" (p. 168).

Se deduce, por tanto, que el cubismo, atendiendo a su manera de construir el espacio -multiplicidad de puntos de vista-y el tratamiento que se imprime a las formas -el uso del cubo es el que da el nombre al movimiento- encarna por primera vez un sistema de representación que trata de acercarse al signo y consecuentemente se aleja del tema figurativo. A este respecto, Apollinaire, en el manifiesto Los pintores cubistas - publicado por primera vez en 1913 y recogido por Cirlot en el volumen Primeras vanguardias. Textos y documentos (1993)-, afirma lo siguiente: "El parecido ya no tiene importancia, ya que el artista lo sacrifica todo por las verdades, por las necesidades de una naturaleza superior que supone sin descubrirla. El tema ya no cuenta o cuenta muy poco" (p. 63).

A pesar de que existe una ruptura evidente de la continuidad renacentista, la continuidad del tema espacial se ve sustituida por una continuidad estructural, por lo que se podría pensar que el cubismo no pierde en ningún momento sus aspiraciones realistas a pesar de la abstracción que ofrece. Golding defiende al respecto, en su texto Cubismo -recogido en el volumen compilado por Stangos Conceptos de arte moderno (1993)-, que lo que caracteriza la fase clásica del movimiento en autores como Braque o Picasso: "Proviene del equilibrio muy cuidadoso que trataron de mantener entre figuración y abstracción" (p. 63)11.

1 De hecho, fue precisamente ese afán de conservar a toda costa el reconocimiento del objeto lo que provocó que los cubistas comenzaran a introducir en su pintura determinadas pistas para facilitar la reconstrucción del tema. En un principio se trataba de algo tan sencillo como un hueco de resonancia o las cuerdas de una guitarra, objetos destinados a que se pudiera distinguir la presencia de un instrumento de música dentro del tejido compositivo en el que este estaba inmerso. Posteriormente, el procedimiento conocido como letras estarcidas - que aparecen por primera vez en la obra de Braque en 1911- pasará a cumplir una función parecida, pretendiendo que a través de la estructura se reconozca el tema. 
A partir del año 1912, señala Golding (1993), esta tendencia a no despreciar totalmente la figuración desembocará en el descubrimiento del collage, que los especialistas en la materia atribuyen conjuntamente a Braque y Picasso:

En no pocas ocasiones Picasso y Braque trabajaron juntos y a los dos se les debe uno de los hallazgos más significativos para todo el arte del siglo XX: el collage. En un primer momento se trató sólo de integrar papeles pegados a la superficie del cuadro, pero más tarde utilizaron todo tipo de elementos provenientes del entorno cotidiano (p. 58).

El hecho de integrar diferentes materiales determinó el paso del llamado cubismo analítico practicado anteriormente con los cubos, hacia el cubismo sintético, que permitía que el espectador percibiera con facilidad una forma global identificable. Pero es precisamente la idea contraria la que interesa destacar: la puesta en evidencia de diferentes materiales y no su ocultación para reforzar el concepto de la fabricación sobre el de la obra misma. Así, la noción del collage, que aboga por que la exhibición de los materiales no se debe esconder, sino todo lo contrario, se convierte en otra de las grandes aportaciones del cubismo para el futuro modelo discursivo con el que las vanguardias saludarán al cine.

\section{Dadá: las costuras de la fabricación y el azar}

El movimiento dadaísta nace en febrero de 1916 con la inauguración en Zúrich del cabaret Voltaire por parte del poeta y filósofo Hugo Ball y alrededor del círculo de hombres que lo frecuentaban: Tristan Tzara, Hans Arps, Georges Grosz, Marcel Janco, etc. Su punto de partida es una profunda negación intelectual y una protesta contra los falsos mitos de la razón positivista.

En relación con el sistema de representación, el movimiento dadaísta no considerará la obra de arte como una unidad global, fijándose más en la fuerza de las partes constitutivas y en el proceso de fabricación. Uno de los grandes personajes del movimiento, Tristán Tzara, explica de manera irónica cómo funciona su método de composición artístico en el Manifiesto sobre el amor débil y el amor amargo - publicado originalmente en 1920 y recogido por De Micheli en Las vanguardias artísticas del siglo XX (1991)- :

Tomad un periódico.

Tomad unas tijeras.

Elegid en el periódico un artículo que tenga la longitud que queráis dar a vuestro poema.

Recortad el artículo.

Recortad con todo cuidado cada palabra de las que forman tal artículo y ponedlas todas en un saquito.

Agitad dulcemente.

Sacad las palabras una detrás de otra, colocándolas en el orden en que las habéis sacado.

Copiadlas concienzudamente.

El poema está hecho. 
Ya os habéis convertido en un escritor infinitamente original y dotado de una sensibilidad encantadora. (p. 269)

Para los dadaístas, todos los diversos materiales que constituyen la obra están en el mismo plano, todos tienen el mismo valor -o ausencia de valor-. El arte nace de la acumulación caótica de elementos inconexos que encuentran su lógica y su equilibrio en el espíritu del artista y del espectador. Béhar (1996) comenta que el hecho de rechazar cualquier jerarquía de valores muestra a los materiales atentos al accidente, al encuentro y al hallazgo, y reconoce a Dadá como el primer movimiento capaz de hacer un uso sistemático de las técnicas resultantes de tal operación, entre las que cita el collage, el fotomontaje y el montaje².

Tanto el rechazo de la noción de obra de arte en favor de la exhibición del proceso de fabricación como la primacía del azar en la reunión de materiales serán -como se verá de inmediato- ideas permeables en la enunciación del modelo de discurso fílmico encontrado con el clásico.

\section{Las ideas futuristas: ritmo y máquina}

Creado por Filippo Tommaso Marinetti, el Futurismo llegó a extenderse por toda Europa ejerciendo una gran influencia en otros movimientos, al defender la primacía del maquinismo y la eliminación drástica del humanismo, como dos de los pilares sobre los que se edifica el nuevo arte. Así nos lo recuerda el paralelismo más conocido del Manifiesto del futurismo escrito por el propio Marinetti -publicado originalmente en 1909 y recogido en el volumen de Cirlot Primeras vanguardias. Textos y documentos (1993)-:

Afirmamos que la magnificencia del mundo se ha enriquecido de una belleza nueva: la belleza de la velocidad. Un automóvil de carreras con su capó adornado de gruesos tubos semejantes a serpientes de aliento explosivo... un automóvil rugiente, que parece correr sobre la metralla, es más hermoso que la Victoria de Samotracia (p. 81).

Más allá de su dimensión política, el movimiento se propone una inmediata ruptura con la gramática, la sintaxis y la métrica de la pintura y las artes tradicionales que, para los futuristas, se habían dedicado hasta el momento a la expresión de unos sentimientos y una belleza estáticos y caducos. En este sentido, la sensación de movimiento es perseguida de manera obsesiva por todos sus adeptos. Conceptos como equilibrio, quietud o armonía no tienen cabida en el nuevo mundo, que los sustituye por los de velocidad, dinamismo, contraste o disonancia. Así, para los futuristas, la idea de Modernidad se en-

2 Las relaciones de los dadaístas con André Bretón serán también determinantes en la formulación del surrealismo y su relación con el cine. Por ejemplo, los juegos conocidos como cadáveres exquisitos ahondan en la idea del collage. Básicamente, se construían del siguiente modo: cada uno de los jugadores dibujaba una cabeza, un tronco o unos miembros, doblando el papel después de que hubiera sido su turno, de forma que no pudiera verse cuál ha sido su contribución. El resultado final generalmente permitía crear extrañas figuras que no escondían su condición de haber sido montadas por trozos, evidenciando una vez más el proceso de fabricación de las partes antes que la unidad del todo que conforman. 
cuentra estrechamente ligada a la de progreso, al que consideran una auténtica panacea, siendo la ciudad una fuente inagotable de inspiración.

Entre su promiscua producción de manifiestos se encuentra uno que relaciona directamente a los futuristas con conceptos teóricos desarrollados posteriormente en el cine: escrito de forma colectiva por varios de sus activistas, el Manifiesto de la cinematografía futurista -publicado en 1916 y reproducido en el volumen colectivo de Romaguera y Alsina Textos y manifiestos del cine (1989) - da cuenta de su predilección por el cine como discurso de la modernidad:

El cinematógrafo futurista contribuirá así a la renovación general, reemplazando a la revista (siempre pedantesca), al drama (siempre previsible) y matando al libro (siempre tedioso y opresivo) (p. 20).

El texto asume que el nuevo medio cinematográfico no tiene nada que ver con las artes que le precedieron y despliega una preocupación ante la búsqueda de su especificidad. Aunque los futuristas no fueron capaces de proponer fórmulas susceptibles de ser llevadas a la práctica ${ }^{3}$, sí supieron desmarcarse claramente del modelo discursivo que el sistema de continuidad cinematográfica desarrollado en Estados Unidos estaba construyendo a lo largo de las dos primeras décadas del siglo, al proclamar una huida de la impresión de realidad característica del cine clásico.

\section{Las experiencias prácticas}

El panorama que se presenta para abordar la praxis llevada a cabo por la vanguardia en las dos primeras décadas de la centuria pasada mediante diferentes experiencias cinematográficas es disperso y heterogéneo, y los autores esgrimen criterios arbitrarios a la hora de clasificar sus aportaciones.

Barbachano (1994) establece un cuadro sinóptico en el que se contempla un conjunto de prácticas fílmicas que se desarrollan desde 1918 hasta 1929 y que agrupadas bajo el nombre de arte mudo aúnan ejercicios cinematográficos como: el cine expresionista, futurista, dadaísta, surrealista, la vanguardia alemana y francesa; el impresionismo; el Kammerspielfilm, la Nueva Objetividad y los filmes subversivos de la escuela cómica estadounidense.

Ortiz y Piqueras (1995) por un lado, hablan de un cine abstracto, cuyos representantes serían Walter Ruttmann, Hans Richter y Viking Eggeling, que se desarrolla en Centroeuropa durante la década de 1920; un cine futurista cuyo centro de operaciones sería Italia; un cine dadaísta caracterizado por un eclecticismo reflejado en obras del propio Richter o fotógrafos como Man Ray; un cine puro con Henry Chomette a la cabeza, cuya finalidad es llegar

3 La gran paradoja del movimiento futurista estriba en su incapacidad para llevar a la práctica sus concepciones teóricas: realizado a principios de 1916, el único largometraje superviviente es Pérfido encanto (Antonio Giulio Bragaglia). Por su parte Bruno Corra y Arnaldo Ginna realizaron en Florencia, entre diciembre de 1916 y enero de 1917, un cortometraje titulado Vida futurista. Aunque ambos filmes fueron anunciados como magnos acontecimientos por la marginal revista afín al movimiento, L' Italia Futurista, no tuvieron repercusión alguna. 
a la esencia del cine a través de la utilización de medios estrictamente cinematográficos; un cine cubista que se manifiesta a través de Fernand Léger y su filme Ballet mecánico (Ballet Mécanique, 1924); un cine expresionista surgido en el contexto de la Alemania de principios de siglo; y un cine surrealista con representantes como Man Ray, Germaine Dulac, Salvador Dalí o Luis Buñuel. Ortiz y Piqueras también proponen la existencia de una escuela impresionista que consigue aproximar la pintura al arte de vanguardia y al fenómeno cinematográfico mediante la integración de la obra dispar de unos cuantos cineastas franceses como Louis Delluc, Germaine Dulac, Marcel L'Herbier, Abel Gance y Jean Epstein:

Lo que los vincula a la vanguardia es la importancia que otorgan a la imagen plástica, el desplazamiento de lo narrativo a un segundo plano y los ritmos musicales, que les llevan a componer verdaderas sinfonías visuales, antes de que éstas alcancen la categoría de independientes en los llamados poemas urbanos (p. 99).

Palacio (1982) considera que la praxis de vanguardia reúne a una serie de artistas plásticos que acuden al cine para resolver los problemas cinéticos que les produce su trabajo en la pintura, y mete en ese saco a autores como Eggeling, Léger, Duchamp, Man Ray, Ruttmann o Richter.

Sánchez-Biosca (1996), por su parte, propone reunir un primer grupo de aportaciones bajo el nombre de teorías y prácticas formativas en las que se incluye el impresionismo francés -representado por Louis Delluc, Germaine Dulac, Jean Epstein, Abel Gance, etc.- cuyo objetivo principal es encontrar un elemento que se consolide como el específico cinematográfico; el segundo bloque propuesto fusiona otros movimientos de vanguardia bajo el calificativo de Absolute filmes, caracterizados por tratar de introducir el elemento temporal y el movimiento en las artes plásticas, entre cuyas filas destacan Hans Richter, Viking Eggeling y Walter Ruttmann.

El panorama trazado es complejo debido a las imbricaciones entre los movimientos, las aportaciones individuales y las distintas consideraciones de los investigadores acerca del estatus vanguardista de los filmes. Sin embargo, existe un objetivo común que une todas las propuestas: el intento de elevar al cinematógrafo al estatuto de arte, y con ello considerarlo un lenguaje -un discurso, algo que no se limita a registrar la realidad y devolverla como tal-, determinando además cuál o cuáles son los elementos específicos que lo separan suficientemente del resto de sistemas de representación de la época.

La búsqueda de la esencialidad cinematográfica no solo se dará a través de la experimentación práctica, sino que también irá acompañada por una incipiente conceptualización teórica de los propios cineastas. La vanguardia se mostrará entonces interesada en la reflexión teórica de técnicas tales como el primer plano, el barrido, la utilización expresiva del encuadre, la variación de la velocidad en el cambio de plano, la alteración del número de fotogramas durante el rodaje, el juego óptico de lentes y el montaje.

\section{El cine como arte: la búsqueda de su específico}

Lindsay (1995) fue el primer autor que en 1915 publicó algo parecido a una teoría del cine encaminada a la búsqueda de sus esencias. Para el autor, el cine es una síntesis de 
la escultura, la pintura y la arquitectura en movimiento, las tres artes que conforman su específico y le diferencian de otros medios artísticos como el teatro y la literatura. El autor alienta así, aunque de forma algo imprecisa, la futura reflexión teórica sobre la existencia de los específicos.

Poco años antes Riccioto Canudo afirmaba en su Manifiesto de las siete artes -publicado en 1911 y recogido en el compilado de Romaguera y Alsina Textos y manifiestos del cine (1989) - que el nuevo medio en imágenes reunía a todas las artes, por lo que debía considerarse, tras la arquitectura, la escultura, la pintura, la poesía, la danza y la música, como el séptimo de las mismas.

El texto de Delluc La fotogenia - publicado en 1920 y recogido en el compilado de Romaguera y Alsina Textos y manifiestos del cine (1989) - señala de forma más concreta a la fotogenia como lo específico del cine y define tal concepto como la afinidad que existe entre cine y fotografía: no es solo la virtud natural de salir bien en la imagen fotográfica -tal y como la entendemos en su acepción coloquial- sino que su riqueza depende del conjunto de elementos que componen la estructura básica del arte cinematográfico. Jean Epstein en su texto A propósito de algunas condiciones de la fotogenia -publicado en 1924 y recogido en el compilado de Romaguera y Alsina Textos y manifiestos del cine (1989)- precisará un poco más el concepto, definiéndolo como: "Cualquier aspecto de las cosas, de los seres y de las almas que aumenta su calidad moral a través de la reproducción cinematográfica" (p. 335).

Posteriormente, León Moussinac en su obra Naissance du cinema (1967) -publicada originalmente en 1925- describirá un nuevo concepto específico al que denomina poema cinegráfico que reúne elementos que determinan, por una parte, el valor propio de cada imagen -lo que el autor llama el ritmo interior-y por otra, el propio valor de la película -al que denomina ritmo exterior-. El interés de su aportación estriba en que el ritmo de un filme no viene dado únicamente por cada imagen aislada, sino también por su sucesión.

Por último, Dulac en su texto Las estéticas. Las trabas. La cinematografía integral -publicado originalmente en 1927 y recogido en el compilado de Romaguera y Alsina Textos y manifiestos del cine (1989)- incide en la idea de que el cine ha sido víctima de estéticas anteriores que le han llevado a despreciar el examen profundo de sus propias posibilidades. Por el simple hecho de poseer el movimiento y una fuerte impresión de realidad, la primera traba que se le impuso al medio fue la de preocupación por narrar. Pero la autora no cree que el cine sea un arte narrativo, por lo que lo define como música de los ojos y considera que el elemento específico que debe regir su técnica es el ritmo visual.

A pesar del tono impreciso y poético de las aportaciones formativas, el elemento específico anhelado por todos estos autores les conduce hacia una embrionaria consideración del montaje como elemento distintivo del cine con respecto a otros medios artísticos. Este montaje nunca es nombrado como tal, a pesar de constituir el elemento rector de la fotogenia o del ritmo visual, pero por primera vez se abandona la idea de asimilar tal operación discursiva a la del concepto de rácord del cine narrativo, haciéndose patente el rechazo hacia la historia y la ocultación de la enunciación como garantía discursiva. 


\section{El exhibicionismo: fragmentación y construcción}

Todas las manifestaciones artísticas referidas pretenden formular las bases del nuevo arte de la Modernidad, y todas terminan encontrando en el cine el dispositivo más adecuado en el que desarrollar un modelo discursivo que rompa definitivamente con el de la representación decimonónica y le separe del prototipo asentado por el clasicismo.

En todos los textos analizados se advierte, además, un comportamiento común referido a la forma en que los filmes adquieren significación, que brevemente se podría describir como la necesidad de exhibir sus materiales para garantizar la posterior vertebración del discurso. Nos encontramos ante la enunciación de un modelo discursivo que se define por su material visible y su forma explícita de organización, por su aspecto de discurso que no oculta tal condición. He aquí pues el rasgo característico de la naturaleza cinematográfica esgrimido desde las vanguardias: la tendencia a la exhibición de su material como estrategia lingüística.

El modelo exhibicionista considera la materia prima fílmica como un conjunto heterogéneo de elementos que son reconocidos precisamente gracias a sus diferencias: el hecho de tener que diseccionar las partes hasta llegar a determinar los componentes mínimos de cada filme -por ejemplo, partiendo de los planos y otras unidades superiores, determinar otros elementos formales como el movimiento, la luz, la línea, la textura, etc.provoca que en muchas ocasiones no se establezca ningún grado de parecido entre el material y su referente, es decir, se renuncie a que la figuración se convierta en un valor semántico con peso. Como consecuencia, este conjunto de materiales formado a partir de los elementos mínimos significantes, no pretende mostrar una faz compacta; muy por el contrario, se esfuerza en exhibir las diferencias que lo convierten en significativo, para asegurar entonces que cada unidad indivisible se transforme en un elemento con potencial discursivo. En este sentido, Sánchez-Biosca (1990) describe la opción exhibicionista de la obra vanguardista -que en su caso denomina analítica-como aquella que procede por mecanismos significantes, cuyo valor es siempre relacional y sustentado en un régimen de oposiciones.

Partiendo de las aportaciones artísticas del período, la formulación discursiva del cine no está, por tanto, en la forma en la que se cosan las partes que organiza -idea vertebral en el modelo clásico que oculta las costuras del montaje-, sino, precisamente, en la opción de fragmentación que permite el reconocimiento y diferenciación del material del que se compone. La idea de un corte en el filme no ha de asimilarse únicamente a la de un cambio de plano, sino que implica también a cualquier otro elemento que al actuar como cesura por oposición a los demás, funcione de manera significante.

Esto explica que, una vez que se ha procedido a la fragmentación, no se haga preciso que los acontecimientos representados o narrados en la pantalla se encubran bajo el amparo de una lógica que los haga verosímiles -condición sine qua non del modelo narrativo hollywoodiense-, puesto que el segundo requisito y rasgo inherente de la exhibición del discurso cinematográfico vanguardista consiste en no ocultar tampoco la mano directora 
que guía la construcción, no ocultar, por tanto, las huellas dejadas en el discurso por el propio autor. Mostrar en definitiva, los mecanismos de la enunciación.

El orden que se impone para garantizar el significado - esa operación que coloquialmente reconocemos con el término montaje- puede imponerse bajo el criterio del movimiento o del ritmo, pero en ningún caso depende de tiranía de la lógica narrativa y el rácord que une los fragmentos.

El mecanismo de este proceso de producción discursivo no es exclusivo del cine, sino que se extiende a todos aquellos movimientos artísticos de principios de siglo en los que se afirma la heterogeneidad del material al tiempo que se renuncia a una pretensión sintética del mismo. Al respecto, Menna (1977) afirma lo siguiente:

La línea analítica del arte moderno ha contribuido de una manera determinante a poner en crisis, incluso en el campo del arte, en el que parecía querer resistir más que en otras partes, una episteme basada en la continuidad y en la semejanza (además de la naturalidad del signo), y ha abierto la vía a una episteme basada en la discontinuidad y en la diferencia (además de la abstracción y la convencionalidad del signo) (p. 75).

El concepto de collage originado en el cubismo, que posteriormente desarrollaron en el ámbito fotográfico los dadaístas berlineses - principalmente Hausmann, Grozs y Heartfield- ya había sido practicado por los fotógrafos victorianos en el siglo XIX o los pioneros de la fotografía como Rejlander o Robinson. Sin embargo, su novedad radica en el uso que las vanguardias le dieron: lejos de poner cuidado en que la imagen resultante fuera armónica, conscientemente se juntaban imágenes radicalmente distintas y discordantes con la finalidad de conseguir que cada una reaccionara frente a la que tenía al lado y obligara al espectador a mirarla de otro modo, siendo así capaz de descubrir cosas antes ocultas por una mirada convencional. Como señala Elder (2013) esta consideración de la diferencia es un claro antecedente del concepto de atracción que desemboca en la teoría del montaje formulada por Sergei M. Eisenstein. Hay una prioridad, por tanto, de los componentes formales de la obra sobre los semánticos a la hora de determinar los criterios lingüísticos que le imprimen sentido.

Con todo, las vanguardias ayudaron a entender que el cine, en su consideración de arte nuevo, no se limita a reproducir los datos de la percepción, de tal manera que: "La forma vuelve a ser retomada bajo el signo fundamental del concepto de construcción" (Oliva, 1991, pp. 162-163). Su exhibicionismo se erige entonces en el modelo significante que va a abrir el camino a las teorías soviéticas sobre el cine, basadas en el trabajo de construcción ejercido por el montaje que cristaliza en los ensayos de Dziga Vertov, Lev Kuleshov, Vladimir Pudovkin y el mismo Sergei M. Eisenstein.

\section{Conclusiones}

El cinematógrafo, en las primeras décadas del siglo XX, permanecía, aún, esperando ser investido por una teoría que le propusiese una forma modélica de discurso alternativa al paradigma clásico heredero de la narrativa decimonónica. 
La convergencia de intereses suscitada entre las vanguardias artísticas emergentes en el momento en el que el cinematógrafo ve la luz favoreció la simbiosis de una fructífera batería de conceptos dispuestos a teorizar sobre el estatus lingüístico del nuevo medio.

El cubismo rompió el sistema de representación renacentista: mediante su propuesta de diagrama estructural se alejó del figurativo y teorizó sobre el collage, aportando al futuro modelo discursivo cinematográfico el exhibicionismo de sus materiales. El movimiento dadaísta hizo lo propio, fijando su atención en la fuerza de las partes constitutivas y en el proceso de fabricación de las obras, ideas aprovechadas en la enunciación del modelo de discurso fílmico contrapuesto al clásico.

La primacía del maquinismo y el protagonismo del movimiento son las dos premisas futuristas que el cine aprovechará en la fragua de su identidad vanguardista. El conjunto de experiencias prácticas en forma de película de los distintos movimientos, aunque heterogéneo y difuso en su ordenación y planteamiento, comparte el objetivo común de elevar al cinematógrafo al estatuto de lenguaje y determinar sus elementos específicos. Las aportaciones formativas de índole teórica también se ocupan de ello, nombrando conceptos como la fotogenia o el ritmo como distintivos del cine, y presuponiendo así que el montaje del modelo discursivo poético opuesto al clásico no tiene necesidad de sustentarse en el rácord característico del cine narrativo.

Todo el conjunto de propuestas artísticas colabora en la formulación de un modelo discursivo exhibicionista cuyas características se resumen en el siguiente axioma: la forma en que su discurso adquiere significación pasa por la necesidad de exhibir sus materiales y su proceso de construcción. El modelo resultante de las aportaciones vanguardistas se define, en definitiva, por la tendencia a la exhibición de su material como estrategia lingüística. 


\section{Bibliografía}

Barbachano, M. (1994). Cine mudo. México: Trillas.

Burch, N. (1991). El tragaluz del infinito (Contribuciones a la genealogía del lenguaje cinematográfico). Madrid: Cátedra.

Apollinaire, G. (1993). Los pintores cubistas. En L. Cirlot. Primeras vanguardias. Textos y documentos (pp. 59-72). Barcelona: Labor.

Béhar, H. (1996). Dadá. Historia de una subversión. Barcelona: Península.

Benet, V. J. (1992). El tiempo de la narración clásica: los films de gánsteres de Warner Bros (1930-1932), Valencia: Filmoteca de la Generalitat valenciana/IVAECM.

Benjamin, W. (1987). La obra de arte en la era de su reproductibilidad técnica. En Discursos interrumpidos I: Filosofía del arte y de la historia (pp. 15-57). Madrid: Taurus.

Berger, J. (1990). El sentido de la vista. Madrid: Alianza.

Bordwell, D., Staiger, J. y Thompson, K. (1997). El cine clásico de Hollywood, estilo y modo de producción hasta 1960. Barcelona: Paidós.

Cirlot, L. (1993). Primeras vanguardias. Textos y documentos. Barcelona: Labor.

Delluc, L. (1989). Fotogenia. En J. Romaguera y H. Alsina (eds.). Textos y manifiestos del cine. Estética. Escuelas. Movimientos. Disciplinas. Innovaciones (pp. 327-333). Madrid: Cátedra.

De Micheli, M. (1991). Las vanguardias artísticas del siglo XX. Madrid: Alianza Editorial.

Dulac, G. (1989). Las estéticas. Las trabas. La cinematografía integral. En J. Romaguera y H. Alsina (eds.). Textos y manifiestos del cine. Estética. Escuelas. Movimientos. Disciplinas. Innovaciones (pp. 89-99). Madrid: Cátedra.

Elder, R. B. (2013): Dada, surrealism, and the cinematic effect. Ontario: Wilfrid Laurier University Press.

Epstein, J. (1989). A propósito de algunas condiciones de la fotogenia. En J. Romaguera y H. Alsina (eds.). Textos y manifiestos del cine. Estética. Escuelas. Movimientos. Disciplinas. Innovaciones (pp. 335-340). Madrid: Cátedra.

Francastel P. (1984). Pintura y sociedad. Madrid: Cátedra.

Golding, J. (1993). Cubismo. En N. Stangos. Conceptos de arte moderno (pp. 45-66). Madrid: Alianza editorial.

Marinetti, F. T. (1993). Manifiesto del futurismo. En L. Cirlot. Primeras vanguardias. Textos y documentos (pp. 80-83). Barcelona: Labor.

Menna, F. (1977). La opción analítica en el arte moderno. Figuras e iconos. Barcelona: Gustavo Gili.

Moussinac, L. (1967). Naissance du cinema. Paris: Français Réunis.

Ortiz, Á. y Piqueras, M. J. (1995). La pintura en el cine. Cuestiones de representación visual. Barcelona: Paidós.

Palacio, M. (1982). Cine y Vanguardia. Contracampo, 31, pp. 18-24.

Romaguera, J. y Alsina, H. (eds.) (1989). Textos y manifiestos del cine. Estética. Escuelas. Movimientos. Disciplinas. Innovaciones. Madrid: Cátedra.

Sánchez-Biosca, V. (1990): Sombras de Weimar, Contribución a la historia del cine alemán 1918-1933. Madrid: Verdoux. 
- (1996). El montaje cinematográfico. Teoría y análisis. Barcelona: Paidós.

Sierra, R. (1995). Tesis doctorales y trabajos de investigación científica. Metodología general de su elaboración y documentación. Madrid: Paraninfo.

Stangos, N. (1993). Conceptos de arte moderno. Madrid: Alianza editorial.

Tzara, T. (1991). Manifiesto sobre el amor débil y el amor amargo. En M de Micheli. Las vanguardias artísticas del siglo XX (pp. 265- 272). Madrid: Alianza Editorial.

V. AA. (1989). La cinematografía futurista. En J. Romaguera y H. Alsina (eds.). Textos y manifiestos del cine. Estética. Escuelas. Movimientos. Disciplinas. Innovaciones (pp. 20-24). Madrid: Cátedra. 